\title{
Access to Multimodal Pain Management for Patients with Chronic Pain: an Audit Study
}

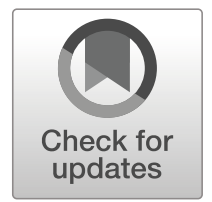

J Gen Intern Med 36(3):818-20

DOI: $10.1007 / \mathrm{s} 11606-020-05866-3$

(C) Society of General Internal Medicine (This is a U.S. government work and not under copyright protection in the U.S.; foreign copyright protection may apply) 2020

\section{INTRODUCTION}

An estimated 50 million Americans experience chronic pain. ${ }^{1}$ To address the complex biopsychosocial aspects of chronic pain and minimize the risks associated with opioid therapy, governmental agencies recommend "timely, early consultation with pain specialists" and a coordinated multimodal approach to pain management. ${ }^{2}$ Effective multimodal care includes medications, restorative therapies, procedures (e.g., joint injections), and behavioral therapy. ${ }^{2}$ However, there are concerns that patients with chronic pain, and particularly those receiving opioid therapy, may not have sufficient access to pain specialists, or to the full range of recommended treatments. ${ }^{2}$ This research sought to quantify access to pain management services for patients receiving opioid therapy for chronic pain.

\section{METHODS}

The study used the "secret shopper" audit methodology during July 2019-September 2019. ${ }^{3}$ The pain clinics were sampled from IQVIA OneKey, a frequently updated healthcare database listing over 9.6 million practitioners, and were drawn from 9 states with varying rates of opioid overdose deaths (Table 1). ${ }^{4}$

Research assistants (RAs) called clinics posing as a patient on long-term opioid therapy (LTOT) seeking care. RAs asked about clinic size, providers available, treatments offered, insurances accepted, referral requirements, wait time for a new patient appointment, and providers' willingness to prescribe opioids, assist with opioid tapering, and/or use buprenorphine to manage pain. Descriptive statistics were produced in $\mathrm{R}$, version 3.5.3 (R Foundation for Statistical Computing). The University of Michigan Institutional Review Board deemed this study not regulated.

\section{RESULTS}

Of 422 specialty pain clinics with working numbers, 366 $(86.7 \%)$ were included after exclusions: being unreachable in

Received January 28, 2020

Revised March 2, 2020

Accepted April 16, 2020

Published online May 6, 2020
3 attempts $(n=35)$, not accepting new patients $(n=10)$, and other reasons (e.g., not serving a general adult population) $(n=11)$.

Of these 366 clinics, $48.1 \%$ did not accept patients with Medicaid. Additionally, 54.9\% required a referral before accepting patients, and another $23.2 \%$ reported that referral requirements varied by insurance. The median wait time for a new appointment was 9 (IQR 4-17) days.

Nearly all clinics $(97.0 \%)$ performed interventional procedures and $77.3 \%$ managed pain medications; at over a third $(36.3 \%)$ of clinics, one or both of these were the only services offered. Physical therapy was offered by $38.3 \%$. A quarter (25.1\%) offered cannabinoid products, including THC and/or $\mathrm{CBD}$, in the 8 states where cannabinoids were legal $(n=355)$. Opioid tapering was offered at 246 clinics (67.2\%), 105 $(42.7 \%)$ of those reported having a buprenorphine provider on staff. Only $12.8 \%$ offered behavioral therapy. Multimodal treatment was rare: only $10.4 \%$ of clinics offered a combination of procedures, medication management, and behavioral therapy (Fig. 1).

\section{DISCUSSION}

This study indicates many barriers to and gaps in care at pain clinics. Almost half of pain clinics did not accept Medicaid, and many required primary care physician (PCP) referrals. Only two-thirds of clinic schedulers responded affirmatively when probed if their providers assist with opioid tapers, and the median appointment waiting period was 9 days. As more patients with chronic pain are transitioned off opioids by their PCPs and PCPs are increasingly unwilling to accept new patients on $\mathrm{LTOT}^{3}$ these access barriers and a 9-day wait time could lead to unintended harms such as worsened pain, withdrawal symptoms, or transition to nonprescribed opioids.

Furthermore, few pain clinics offered behavioral therapy, which can improve pain-coping skills and address maladaptive behaviors commonly associated with pain-related disability. ${ }^{2}$ Interestingly, more clinics offered cannabinoid products than offered behavioral therapy, despite evidence for cannabinoids as a treatment for chronic pain being less robust than that for behavioral therapy. ${ }^{5}$ The observed focus on procedural treatments and lower rates of medication management and behavioral therapy may be particularly unhelpful to patients with comorbid substance use disorders. 
Table 1 Clinic Attributes: Treatments Offered and Barriers to Care

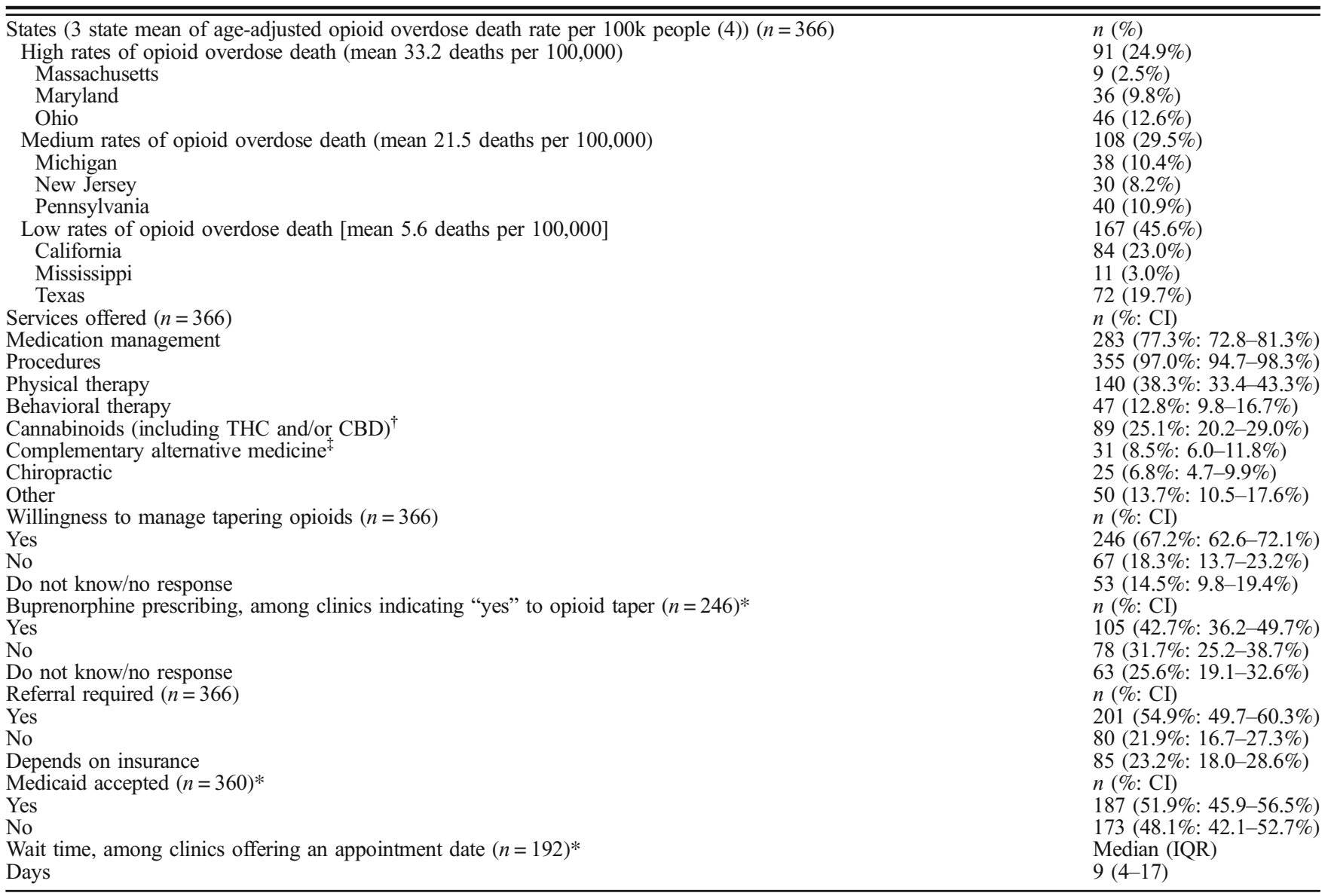

*Excluded clinics did not respond or did not receive the prompt. Percentages are based on the provided $n$ value

†Percentages were calculated for only the clinics in states where some form of cannabis derivative is legal (i.e., full legalization, medical legalization, or CBD oil only)

$\not$ For example, cupping and/or acupuncture

Barriers to providing multimodal care likely include inadequate reimbursement for behavioral therapy and other non-procedural treatments, lack of trained providers, and opioid-related stigma. ${ }^{2}$ Limitations to this study included only contacting pain clinics from the IQVIA database, and in 9 states, which may not be representative of all pain clinics. In addition, information was provided by front desk staff, who may be unaware of some services. However, this

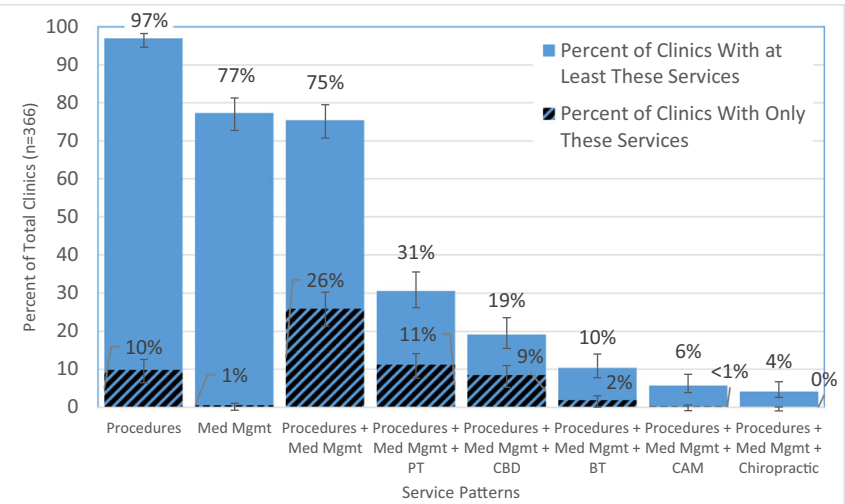

Figure 1 Percentage and $95 \%$ CI of select service patterns offered exclusively and in combination with additional services. This graph presents selected service patterns. Service patterns are presented both exclusively [diagonal] (e.g., "Procedures + Med Mgmt" are clinics that only offer those two services and no others) and non-exclusively [solid bars]. Med Mgmt, medication management; PT, physical therapy; CBD, any cannabinoid or cannabis derivative (e.g., CBD oil); BT, behavioral therapy; CAM, complementary alternative medicine (e.g., cupping, acupuncture). 
is consistent with the information real patients receive. Thus, while timely multimodal specialty care may be the ideal treatment model, it is currently unavailable to the majority of patients.

Acknowledgments: We would like to acknowledge Giuliana Bresnahan, Danielle Helminski, and Avani Yaganti for assisting with data collection and Adrianne Kehne for her thoughtful edits.

Pooja Lagisetty, MD, MSc

Stephanie Slat, BS

Jennifer Thomas, BS

Colin Macleod, MA

Department of Internal Medicine, University of Michigan,

Ann Arbor, MI, USA

Pooja Lagisetty, MD, MSc

Amy SB Bohnert, $\mathrm{PhD}$

Center for Clinical Management and Research, Ann Arbor

VA Hospital, Ann Arbor, MI, USA

Goodarz Golmirzaie, MD

Amy SB Bohnert, PhD

Department of Anesthesiology, University of Michigan,

Ann Arbor, MI, USA

Amy SB Bohnert, PhD

Department of Psychiatry, University of Michigan,

Ann Arbor, MI, USA

Corresponding Author: Pooja Lagisetty, MD, MSc; Department of Internal Medicine, University of MichiganAnn Arbor, MI, USA (e-mail: lagiset@med.umich.edu).

Funding Information This work was funded by the Michigan Health Endowment Fund (PAL) and by the National Institute On Drug Abuse of the National Institutes of Health Award (grant numbers K23 DA047475 (PAL)).

\section{Compliance with Ethical Standards:}

The University of Michigan Institutional Review Board deemed this study not regulated.

Conflict of Interest: The authors declare that they do not have a conflict of interest.

\section{REFERENCES}

1. Dahlhamer J, Lucas J, Zelaya, C, et al. Prevalence of Chronic Pain and High-Impact Chronic Pain Among Adults - United States, 2016. MMWR Morb Mortal Wkly Rep. 2018;67:1001-1006. https://doi.org/10.15585/ mmwr.mm6736a2

2. U.S. Department of Health and Human Services (2019, May). Pain Management Best Practices Inter-Agency Task Force Report: Updates, Gaps, Inconsistencies, and Recommendations. Retrieved from U. S. Department of Health and Human Services website: https://www.hhs. gov/ash/advisory-committees/pain/reports/index.html

3. Lagisetty PA, Healy N, Garpestad C, Jannausch M, Tipirneni R, Bohnert ASB. Access to primary care clinics for patients with chronic pain receiving opioids. JAMA Netw Open. 2019 2(7):e196928. https://doi. org/10.1001/jamanetworkopen.2019.6928

4. Henry $\mathbf{J}$ Kaiser Family Foundation. Opioid Overdose Death Rates and All Drug Overdose Death Rates per 100,000 Population (Age-Adjusted). https://www.kff.org/other/state-indicator/opioid-overdose-death-rates. Published January 10, 2019. Accessed March 21, 2019.

5. Meng H, Johnston B, Englesakis M, Moulin DE, Bhatia A. Selective cannabinoids for chronic neuropathic pain: A systematic review and metaanalysis. Anesth Analg. 2017;125(5):1638-1652. https://doi.org/10. 1213/ANE.0000000000002110

Publisher's Note: Springer Nature remains neutral with regard to jurisdictional claims in published maps and institutional affiliations. 